\title{
Soy, milk and wheat allergy
}

Itu Komei

From Food Allergy and Anaphylaxis Meeting 2011

Venice, Italy. 17-19 February 2011

Food allergies affect $5-10 \%$ of infants, $2-5 \%$ of toddlers, and $1.3-2.6 \%$ of school children in Japan. Egg, milk and wheat are the major three food allergens. Soybean is one of the eight foods causing immediate allergic reactions, sometimes anaphylaxis. Fermented soybeans, miso and shoyu, are used in most of the traditional Japanese foods, and exposure to soybeans in Japanese children begins as one of the first solid foods, typically in the form of tofu. Sensitization to soy, milk and wheat occurs in many atopic babies. Some are the primary sensitizations to the foods through oral or cutaneous route, but others may be the secondary sensitization through cross-reactive foods or pollens.

Component-specific IgE tests provide us more sensitive and specific diagnostic tools. We have found that casein, one of the most classically known allergen components in milk, can be a more specific marker in the diagnosis of milk allergy, especially in the older children. Recombinant $\omega-5$ gliadin ImmunoCAP ${ }^{\circledR}$ provides almost $100 \%$ positive predictive value of immediate type wheat allergy in children at $17.5 \mathrm{kUA} / \mathrm{L}$, as well as wheatdependent exercise-induced anaphylaxis in adults. Gly m 5 and Gly $m 6$ from soybean can be a marker of severe primary soy allergy in Japanese children. On the other hands, patients with secondary soy allergy in adults, who have allergic reactions exclusively to soy milk, but not to tofu, are predominantly sensitized to Gly m 4 (PR-10), possibly due to the cross-reactive pollen allergens.

In conclusion, allergen component testing is an excellent clinical tool from a diagnostic point of view but also provide us with new insights into food allergy.

Published: 12 August 2011

Aichi Children's Health and Medical Center, Department of Allergy, Obu, Japan

Ciomed Central

(c) 2011 Komei; licensee BioMed Central Ltd. This is an open access article distributed under the terms of the Creative Commons Attribution License (http://creativecommons.org/licenses/by/2.0), which permits unrestricted use, distribution, and reproduction in any medium, provided the original work is properly cited.
doi:10.1186/2045-7022-1-S1-S39

Cite this article as: Komei: Soy, milk and wheat allergy. Clinical and

Translational Allergy 2011 1(Suppl 1):S39. and take full advantage of:

- Convenient online submission

- Thorough peer review

- No space constraints or color figure charges

- Immediate publication on acceptance

- Inclusion in PubMed, CAS, Scopus and Google Scholar

- Research which is freely available for redistribution 